\title{
Michael addition of phthalimide and saccharin to enantiomerically pure diesters of BINOL and TADDOLs derivatives under microwave conditions
}

\author{
Andrea R. Costantino ${ }^{a b} *$, Sandra D. Mandolesi ${ }^{a}$, Liliana C. Koll ${ }^{\text {ab }}$ \\ a Instituto de Química del Sur (INQUISUR), Departamento de Química, Universidad Nacional del \\ Sur, Avenida Alem 1253, 8000 Bahía Blanca, Argentina \\ ${ }^{b}$ CONICET, Argentina. E-mail: andrea.costantino@uns.edu.ar; Ickoll@criba.edu.ar ; \\ sdmando@criba.edu.ar \\ * Author to whom correspondence should be addressed.
}

\begin{abstract}
One of the most important reactions in synthetic organic chemistry is the conjugate addition of nucleophilic species to the $\beta$-carbon of $\alpha, \beta$-unsaturated systems. This process allows the construction of carbon backbones and very valuable from a synthetic point of view. Several attempts in the generation of $\beta$-amino derivatives have been reported and the aza-Michael addition reaction is widely recognized as one of the most important carbon-nitrogen bondforming reaction in organic synthesis. Most of these products have special properties. Thus, this reaction provides a simple and appealing route toward the synthesis of $\mathrm{N}$-alkyl derivatives of these compounds. In this work, we propose to study the aza-Michael reaction under microwave condition between saccharine and phthalimide with enantiomerically pure diesters of BINOL and TADDOLs derivatives. ${ }^{1}$ This methodology allowed us to obtain chiral di-addition products of great synthetic interest with good yields and relatively short reaction times.
\end{abstract}

Keywords. Aza-Michael addition, diesters, TADDOL, BINOL

\section{Introduction.}

The conjugate addition of nucleophiles to electron-deficient alkenes is an important reaction and has wide application in organic synthesis. Particularly, addition of amines to $\alpha, \beta-$ unsaturated esters produce $\beta$-amino derivatives which have become increasingly important to the study of natural products and pharmaceutical areas. In recent years, the synthesis of these derivatives with different substitution patterns on the carbon chain has become a field of growing interest in organic synthesis.

The Michael conjugate addition reaction (Scheme 1) has been a useful tool for organic, medicinal, and biochemistry for several decades. This transformation is an efficient and commonly used route to the formation of $\mathrm{C}-\mathrm{C}, \mathrm{C}-\mathrm{O}, \mathrm{C}-\mathrm{N}$, and $\mathrm{C}-\mathrm{S}$ bonds and it facilitates, for example, the synthesis of important amino alcohols and versatile intermediates for a large number of natural products, heterocycles, peptides, and chiral auxiliaries. ${ }^{2}$ The aza-Michael reaction is considered a very efficient and versatile method of creating new $\mathrm{C}-\mathrm{N}$ bond and one of the shortest routes to $\beta$ amino carbonyl derivatives. In fact, it is one of the most widely used reactions in modern organic synthesis of biologically active compounds because it benefits due to good atom economy. Moreover, aza-Michael addition is of remarkable significance in asymmetric synthesis as documented by the various asymmetric aza-Michael protocols available to perform this reaction in highly stereoselective form as well as applied to the total synthesis of natural products. Although 
Michael addition of amines to $\alpha, \beta$-unsaturated acids failed, their addition to $\alpha, \beta$-unsaturated nitriles, esters and ketones is known. ${ }^{3}$

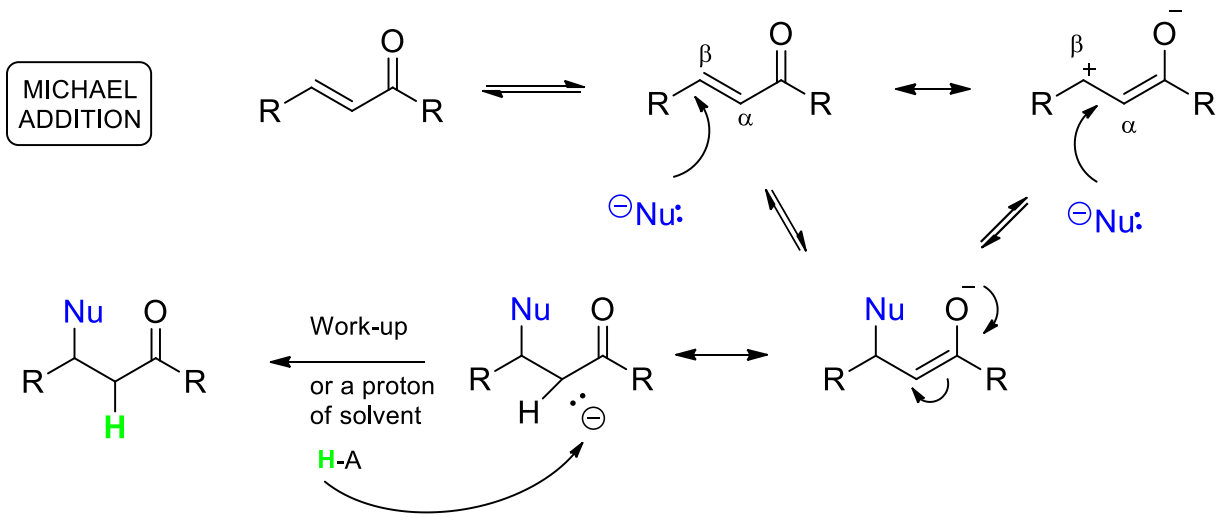

Scheme 1

Michael addition of phthalimide and saccharin to $\alpha, \beta$-unsaturated esters is significant as this reaction provides a simple and appealing route toward synthesis of $\mathrm{N}$-alkyl derivatives of these compound. Some $\mathrm{N}$-alkyl phthalimide and saccharin derivatives are important in medicinal chemistry. These compounds can act as antipsychotic, anti-inflammatory and lipid lowering agents, among others. Furthermore, saccharin derivatives can complex with various metal ions, such as $\mathrm{Mg}^{2+}, \mathrm{Ca}^{2+}, \mathrm{Sr}^{2+}, \mathrm{Pd}^{2+}, \mathrm{Cu}^{2+}$.

Conjugate addition of phthalimide and saccharin to $\alpha, \beta$-unsaturated esters also affords protected $\beta$-amino acids. This class of compounds are essential components in many bioactive compounds and drugs scaffolds, including $\beta$-peptides, imeriamine (hypoglycemic and antiketogenic agent, Figure 1), vitamin $B_{3}$ (Figure 1), cryptophycin (antitumor), and TAN-1057 A (antibiotic). Moreover, the synthesis of $\beta$-amino esters has gained considerable attention due to the possibility of generate intermediates for the synthesis of natural products, aminoalcohols, diamines, $\beta$-lactams, $\beta$-amino acid derivatives and other molecules containing nitrogen. ${ }^{5}$ Thus, this reaction provides a simple and appealing route toward synthesis of $N$-alkyl derivatives of these compounds.

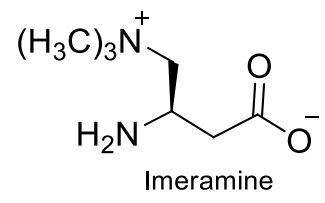<smiles>CC(C)(C)[C@H](O)C(=O)NCCC(=O)O</smiles>

Figure 1

Based on previous studies, ${ }^{4}$ we decided to study the aza-Michael reaction in the presence of catalytic amount of zinc oxide and tetrabutylammonium bromide (TBAB) under microwave condition between saccharine and phthalimide with enantiomerically pure diesters of BINOL and TADDOLs derivatives. ${ }^{1}$ 


\section{Results and Discussions}

In order to obtain the optimized reaction conditions, we have studied the reaction of phthalimide with (S)-1,1'-binaphthyl-2-2'-diyl diacrylate (1a) as a model reaction to provide compound 2a (Table 1). For this purpose, at first, the effect of different amounts of phthalimide, $\mathrm{ZnO}$ (as catalyst) and TBAB in several volumes of solvent, were examined under microwave to evaluate their capabilities. The results are summarized in Table 1. As can be seen in entry 5, higher conversion in shorter reaction time was obtained when 3 eq. of phthalimide, $55 \%$ of $\mathrm{ZnO}, 1$ eq. of TBAB and $1 \mathrm{ml}$ of solvent were used.

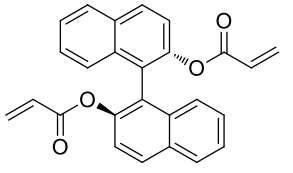

1a

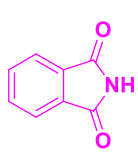

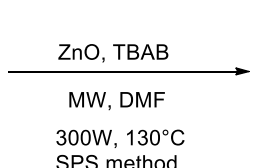

SPS method

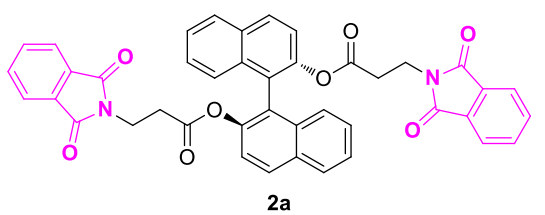

2a

Table 1

\begin{tabular}{|c|c|c|c|c|c|c|}
\hline Entry & Eq. of phthalimide & $\% \mathrm{ZnO}$ & Eq.of TBAB & mL Solvent & Time $^{a}$ & $\%$ Conversion \\
\hline 1 & 2.2 & 40 & 0,6 & 2.5 & $60 \min \mathrm{MW}$ & 64,1 \\
\hline 2 & 2.2 & 40 & 0,6 & 1 & $60 \mathrm{~min} . \mathrm{MW}$ & 68,3 \\
\hline 3 & 2.2 & 80 & - & 2.5 & $60 \mathrm{~min} . \mathrm{MW}$ & 24.5 \\
\hline 4 & 2.2 & 80 & 0,6 & 2.5 & $60 \min . \mathrm{MW}$ & 63,1 \\
\hline 5 & 3 & 55 & 1 & 1 & $60 \mathrm{~min} . \mathrm{MW}$ & 80,4 \\
\hline 6 & 3 & - & - & 1 & $60 \mathrm{~min} . \mathrm{MW}$ & $-{ }^{c}$ \\
\hline 7 & 3 & 55 & 1 & 1 & 96 hr.t. & 65,5 \\
\hline 8 & 3 & 55 & 1 & 1 & $12 \mathrm{~h} 130^{\circ} \mathrm{C}$ & 69,0 \\
\hline
\end{tabular}

MW: microwave irradiation or thermal conditions; Determinated by ${ }^{1} \mathrm{H}-\mathrm{NMR}$; No reaction observed.

The role of TBAB and ZnO were too evaluated. As shown in entry 6, Table 1, the presence of $\mathrm{ZnO}$ catalyst and $\mathrm{TBAB}$ is absolutely necessary. Even though mainly $\mathrm{ZnO}$ is required, the absence of $T B A B$ in the reaction media gave low reaction yield even by prolonging the reaction time (entry 3 ). Thus, the presence of TBAB in our reaction is significantly critical. TBAB causes a change in the reaction media whose resemblance is not far from that of ionic liquids. TBAB absorbs the microwave radiation as well as generates heat in situ so the temperature is increased to a value higher than its melting point $\left(100-103^{\circ} \mathrm{C}\right) .{ }^{4}$

From these results it can be seen that the best method is microwave irradiation. Besides, regarding the volume of solvent used, the method that uses less solvent is more efficient (entry 5 ).

After this, the same substrate was used to study the effect of substituents on $\alpha$ and $\beta$ position (Table 2). 
<smiles>[R]C=C([R])C(=O)Oc1ccc2ccccc2c1-c1c(OC(=O)C([R])=C[R])ccc2ccccc12</smiles>

1a-f

Table 2

\begin{tabular}{|c|c|c|c|c|c|c|}
\hline Entry & Substrate & $\mathbf{R}^{1}$ & $\mathbf{R}^{2}$ & Nucleophile & Time & Yield \\
\hline 1 & $1 a$ & $\mathrm{H}$ & $\mathrm{H}$ & Phthalimide & $20 \mathrm{~min}$ & $55 \%$ \\
\hline 2 & $1 b$ & $\mathrm{H}$ & $\mathrm{H}$ & Saccharin & $60 \mathrm{~min}$. & $17 \%$ \\
\hline 3 & 1c & $\mathrm{CH}_{3}$ & $\mathrm{H}$ & Phthalimide & $60 \mathrm{~min}$. & $14 \%$ \\
\hline 4 & $1 d$ & $\mathrm{CH}_{3}$ & $\mathrm{H}$ & Saccharin & $90 \mathrm{~min}$. & $-{ }^{a}$ \\
\hline 5 & $1 e$ & $\mathrm{H}$ & $\mathrm{Ph}$ & Phthalimide & $90 \mathrm{~min}$. & $-^{a}$ \\
\hline 6 & $1 f$ & $\mathrm{H}$ & $\mathrm{Ph}$ & Saccharin & $90 \mathrm{~min}$. & $-^{a}$ \\
\hline
\end{tabular}

From entries 1 and 2, it could be suggested that when the double bond is terminal (1a and 1b) it is more reactive to both phthalimide and saccharin reagents. In the case of $(S)-1,1$ binaphthyl-2-2'-diyl dimetacrylate (1c and $1 \mathbf{d}$ ), the reaction with phthalimide gives low yields and longer reaction times. For (S) -1,1-binaphthyl-2-2'-diyl- (Z) -3-phenyl-2-propenoate (1e and 1f), no reaction was observed for both reagents. Besides, saccharin is less reactive than phthalimide under these conditions and with these substrates. In the case of product $\mathbf{2 c}$, from the reaction between (S)-1,1-binaphthyl-2-2'-diyl dimetacrylate and phthalimide, two stereocenters are generated, forming four diastereomers and they are easily seen in the ${ }^{1} \mathrm{H}$ and ${ }^{13} \mathrm{C}-\mathrm{NMR}$, as shown in Figure 2.

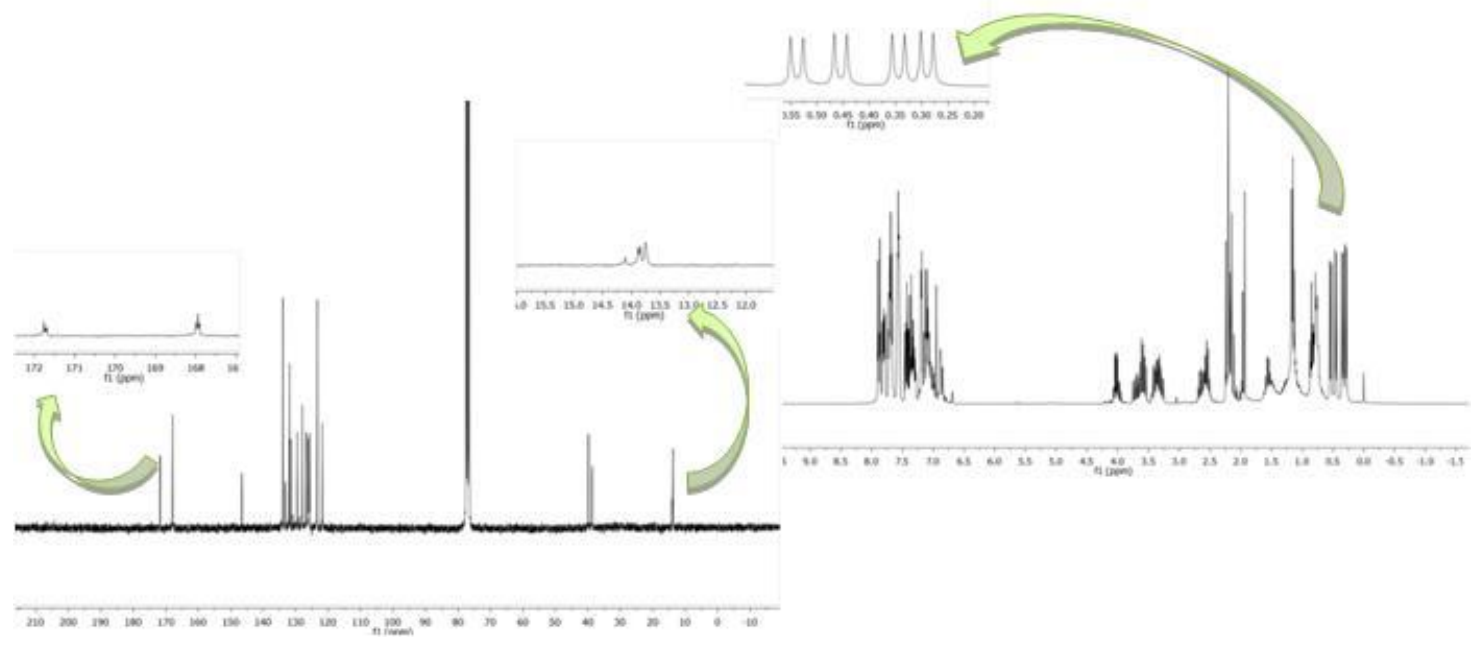




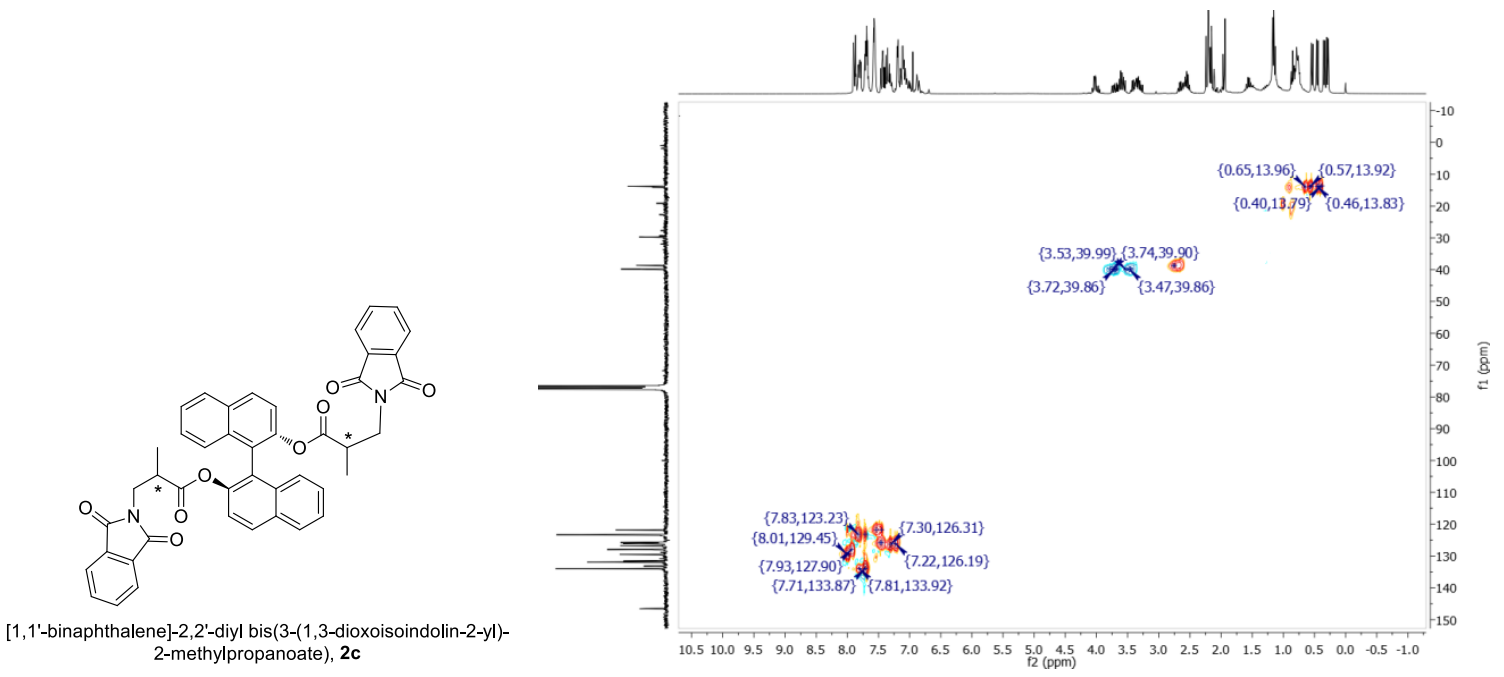

Figure 2

Finally, the reactions of phthalimide and saccharin were performed with the enantiomerically pure substrates $\mathbf{1 a}, \mathbf{3} \mathbf{a}$ and $\mathbf{5 a}$, obtained from the corresponding diols (Figure $\mathbf{3}$ ).<smiles>C=CC(=O)Oc1ccc2ccccc2c1-c1c(OC(=O)C=C)ccc2ccccc12</smiles>

1a<smiles>C=CC(=O)OC(c1ccccc1)(c1ccccc1)C1OC(C)(C)OC1[C@H]1OC(C)(C)O[C@H]1C(OC(=O)C=C)(c1ccccc1)c1ccccc1</smiles>

3a<smiles>C=CC(=O)O[C@H]1[C@@H](OC(=O)C=C)C(c2ccccc2)(c2ccccc2)OC1(c1ccccc1)c1ccccc1</smiles>

$5 a$

Figure 3

All of the new derivatives with $\mathrm{C}_{2}$ symmetry obtained, together with the corresponding yields and optical rotations are shown in Figure 4.

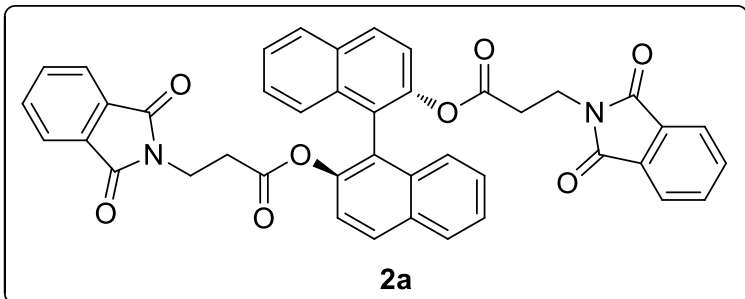

Yield 55\%

$[\alpha]_{D}^{25}=-25,23\left(\mathrm{c}=0,22, \mathrm{CHCl}_{3}\right)$

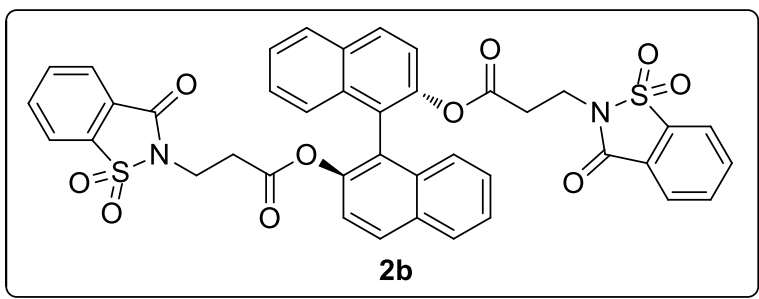

Yield $16 \%$

$[\alpha]_{D}^{25}=-13,6\left(\mathrm{c}=0,85, \mathrm{CHCl}_{3}\right)$ 

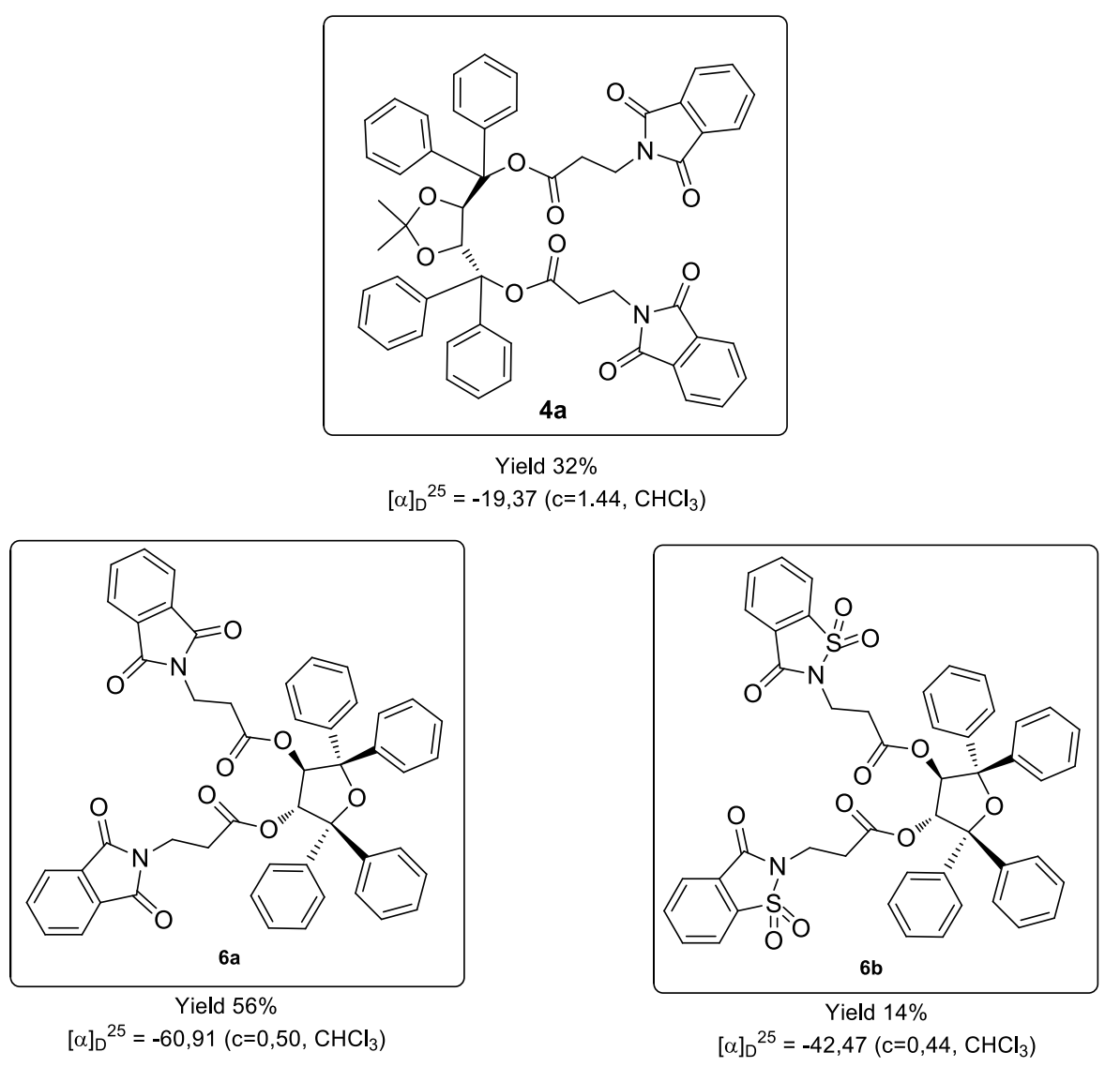

Figure 4

\section{Conclusions}

In summary, we have developed the synthesis of new compounds with $C_{2}$ symmetry through Michal addition of phthalimide and saccharin to various chiral bis-acrylic acid esters under microwave conditions. This new method affords $N$-alkyl derivatives of phthalimide and saccharin as biologically interesting compounds in short reaction times.

\section{Experimental Section}

Unless otherwise noted, all reagents were purchased from commercial suppliers and used without purification. Thin layer chromatography was performed on Merck precoated silica gel 60 F254 plates and visualization was accomplished with UV light and/or 5\% ethanol solution of phosphomolibdic acid. NMR spectra were recorded on a Bruker ARX 300 Multinuclear instrument, using $\mathrm{CDCl}_{3}$ as solvent. Microwave reactions were carried out in a microwave CEM Discover ${ }^{\circledR}$ at $300 \mathrm{~W}, 130^{\circ} \mathrm{C}$.

\section{General methods}

To a well ground mixture of compounds consisting of imide $(2.2 \mathrm{mmol})$, TBAB $(0.6 \mathrm{mmol})$ and $\mathrm{ZnO}(55 \% \mathrm{~mol})$ with $8 \mathrm{~mL}$ of DMF in a microwave vessel, was added acrylic acid esters (1 
$\mathrm{mmol}$ ) and mixed carefully with a small rod. The mixture was irradiated in the microwave oven at $300 \mathrm{~W}$ for the times reported in Table $\mathbf{1}$ and Table 2. The microwave was programmed to give a maximum internal temperature to $130{ }^{\circ} \mathrm{C}$. Afterward, the reaction mixture was washed with water $(3 \times 30 \mathrm{~mL})$ and ethyl acetate $(3 \times 30 \mathrm{~mL})$. The combined organic extracts were dried over $\mathrm{MgSO}_{4}$ and the solvent was removed under vacuum. The crude product was purified by column chromatography on silica gel with $n$-hexane/EtOAc.

\section{Acknowledgments}

This work was supported by grants from ANPCyT (Capital Federal, Argentina), CONICET (Buenos Aires, Argentina) and Universidad Nacional del Sur (Bahía Blanca, Argentina). A fellowship from CONICET to ARC is acknowledged.

\section{References}

${ }^{1}$ (a) Costantino, A. R.; Ocampo, R.; Montiel Schneider, M. G.; Fernandez, G.; Mandolesi, S. D.; Koll, L. C.; Synthetic Communications, 2013, 49, 3192-3202; (b) Gerbino, D. C.; Koll, L. C.; Mandolesi, S. D.; Podestá, J. C. Organometallics 2008, 27, 660-665.

${ }^{2}$ Fetterly, B. M.; Jana, N. K.; Verkade, J. G. Tetrahedron, 2006, 62, 440-456.

${ }^{3}$ Azizi, N.; Saidi, M. R. Tetrahedron 2004, 60, 383-387.

${ }^{4}$ Zare,A.; Hasaninejad, A.; Khalafi-Nezhad, A.; Moosavi Zare, A. R.; Parhami, A.; Nejabatc, G. R. ARKIVOC 2007 (i) 58-69.

${ }^{5}$ Ranu, B. C.; Banerjee, S. Tetrahedron Letters, 2007, 48, 141-143. 